\title{
The comparative efficiency of ad valorem and specific taxes under monopoly and monopsony
}

\author{
Stephen F. Hamilton \\ Department of Agricultural Economics, Kansas State University, 326 Waters Hall, Manhattan, KS 66506-4011, USA
}

\begin{abstract}
It is well known that ad valorem taxes welfare-dominate specific taxes under monopoly. This paper demonstrates that the comparative welfare ranking of the two instruments reverses under monopsony. The relative performance of alternative tax forms is thus highly sensitive to whether the buyer or seller has market power.
\end{abstract}

Keywords: Monopoly; Monopsony; Tax efficiency; Ad valorem tax; Specific tax

\section{Introduction}

A familiar and oft-cited result on tax efficiency in noncompetitive environments is the superior performance of an ad valorem tax over an equal-yield specific tax. While it is well known that the two taxes yield identical outcomes in perfectly competitive environments, Wicksell (1950, originally published in 1896) and later Suits and Musgrave (1953) demonstrate that an ad valorem tax welfare dominates an equal-yield specific tax in the monopoly case. Recently, Delipalla and Keen (1992) extend this result to various circumstances of homogeneous product oligopoly and Skeath and Trandel (1994) strengthen the claim by establishing the superiority of ad valorem over specific taxes under a more stringent welfare criterion of Pareto optimality. This paper demonstrates that the welfare domination of an ad valorem tax over an equal-yield specific tax, while true under monopoly and oligopoly, fails to hold under monopsony.

The basic argument for the welfare dominance of an ad valorem tax centers on the relative efficiency with which ad valorem and specific taxes achieve a given transfer of revenue. That is, for a given specific tax imposed on a monopoly, it is possible to find an ad valorem tax that raises the same amount of revenue but that results in greater equilibrium output and, therefore, greater welfare. The following section demonstrates that the welfare ranking of the two policy instruments reverses under 
monopsony. For a given ad valorem tax levied on a monopsony, an equal-yield specific tax results in greater equilibrium output and greater welfare. Hence, the comparative efficiency of ad valorem and specific taxes does not yield global welfare implications in noncompetitive environments: the relative efficiency of the taxes depends critically on whether it is the buyer or seller who has market power.

\section{The model}

The following comparative efficiency analysis is based on two primary cases. The first case, that of a monopoly seller, is the situation typically considered in the literature. The second case, that of a monopsony buyer, is analogous to the first situation and has remained, perhaps for this reason, relatively unexplored.

Comparative efficiency results are derived by examining the relative yields of an ad valorem tax and a specific tax that result in the same final output and price. It follows directly that the higher yielding tax is associated with greater equilibrium output and greater welfare for a given amount of revenue collected.

Let $R(Y)$ denote the tax yield associated with a given level of output, $Y$. Under a specific tax, $R(Y)=t^{u} Y$ and $R_{Y}(Y)=t^{u}$, where $t^{u}$ is the specific tax rate. Under an ad valorem tax, $R(Y)=t^{a} P(Y) Y$ and $R_{Y}(Y)=t^{a}\left[P(Y)+Y P_{Y}(Y)\right]$, where $P(Y)$ is the market price schedule and $t^{a}$ is the ad valorem tax rate.

Next, consider an industry subject to taxation in which an economic agent $i$ sells a certain product to a second agent $j$. For a given market quantity, agent $i$ incurs production costs of $C(Y)$, with $C_{Y}(Y)>0$ and $C_{Y Y}(Y)>0$, while agent $j$ receives total benefits of $B(Y)$, with $B_{Y}(Y)>0$ and $B_{Y Y}(Y)<0$. The welfare criterion is the standard Marshallian surplus measure, $W(Y)=B(Y)-C(Y)$.

Case 1. Consider the case in which agent $i$ is a monopolist and agent $j$ behaves competitively. In this case, the profit of agent $i$ is

$$
\pi^{i}(Y)=P(Y) Y-C(Y)-R(Y),
$$

where the market price schedule, $P(Y)$, is the marginal benefit function (i.e., inverse demand function) of agent $j$,

$$
P(Y)=B_{Y}(Y)
$$

Substituting (2) into (1), the first-order necessary condition for a maximum is

$$
B_{Y}(Y)+Y B_{Y Y}(Y)-C_{Y}(Y)=R(Y) .
$$

Let $Y^{*}$ denote the equilibrium level of output defined by (3). A comparison of ad valorem and specific taxes at $Y^{*}$ must equate the marginal revenue transfer, $R_{Y}\left(Y^{*}\right)$, between the two policy instruments, which implies

$$
t^{u}=t^{a}\left[B_{Y}\left(Y^{*}\right)+Y^{*} B_{Y Y}\left(Y^{*}\right)\right] .
$$

The yield under a specific tax is $R^{u}\left(Y^{*}\right)=t^{u} Y^{*}$, which, using (2) and (4), equals 


$$
t^{a} Y^{*} B_{Y}\left(Y^{*}\right)+t^{a}\left(Y^{*}\right)^{2} B_{Y Y}\left(Y^{*}\right)=R^{a}\left(Y^{*}\right)+t^{a}\left(Y^{*}\right)^{2} B_{Y Y}\left(Y^{*}\right)
$$

Therefore,

$$
R^{u}\left(Y^{*}\right)-R^{a}\left(Y^{*}\right)=t^{a}\left(Y^{*}\right)^{2} B_{Y Y}\left(Y^{*}\right)<0
$$

where the inequality follows from the concavity of the benefit function. Expression (5) indicates that the yield under an ad valorem tax exceeds that under a specific tax at a given equilibrium price and quantity. Equivalently, an ad valorem tax is associated with greater output and a lower market price relative to an equal-yield specific tax. This argument is the basis of the familiar conclusion that an ad valorem tax welfare dominates an equal-yield specific tax under monopoly.

Case 2. Next consider the case in which agent $i$ behaves competitively and agent $j$ is a monopsonist. In this case, the profit of agent $j$ is

$$
\pi^{j}(Y)=B(Y)-P(Y) Y-R(Y)
$$

where the market price schedule, $P(Y)$, is the marginal cost function (i.e., inverse supply function) of agent $i$,

$$
P(Y)=C_{Y}(Y)
$$

Substituting (7) into (6), the first-order necessary condition for a maximum is

$$
B_{Y}(Y)-C_{Y}(Y)-Y C_{Y Y}(Y)=R_{Y}(Y)
$$

If $Y^{*}$ denotes the monopsony output level associated with (8), then, for alternative specifications of the tax instrument, it must be true that

$$
t^{u}=t^{a}\left[C_{Y}\left(Y^{*}\right)+Y^{*} C_{Y Y}\left(Y^{*}\right)\right]
$$

The yield under a specific tax is given by $R^{u}\left(Y^{*}\right)=t^{u} Y^{*}$, by which (7) and (9) equals

$$
t^{a} Y^{*} C_{Y}\left(Y^{*}\right)+t^{a}\left(Y^{*}\right)^{2} C_{Y Y}\left(Y^{*}\right)=R^{a}\left(Y^{*}\right)+t^{a}\left(Y^{*}\right)^{2} C_{Y Y}\left(Y^{*}\right) .
$$

Therefore,

$$
R^{u}\left(Y^{*}\right)-R^{a}\left(Y^{*}\right)=t^{a}\left(Y^{*}\right)^{2} C_{Y Y}\left(Y^{*}\right)>0
$$

where the inequality follows from the convexity of the cost function. It follows directly from (10) that a specific tax welfare dominates an ad valorem tax under monopsony. Because the market price under monopsony is identified with the inverse supply function, as opposed to the inverse demand function under monopoly, an increase in the quantity purchased by a monopsonist increases the marginal tax rate, which thereby reverses the comparative ranking of the taxes. 


\section{Policy implications}

The reversal of the welfare ranking in the monopoly and monopsony cases is rather intuitive. A monopolist does not have a supply function and thus perceives the effect of a change in output on the tax rate to be determined by the market demand function. Conversely, a monopsonist does not have a demand function and thus perceives the effect of a change in output on the tax rate to be determined by the market supply function. As a result, an ad valorem tax, which assesses a marginal tax rate that varies with the equilibrium market price, increases the elasticity of the after-tax demand function under monopoly but makes the after-tax supply function more inelastic under monopsony.

The relative performance of ad valorem and specific taxes in noncompetitive environments thus hinges on whether the market price schedule is given by a market supply or market demand function. The conventional wisdom that an ad valorem tax welfare dominates an equal-yield specific tax under imperfect competition is true only if the seller is the agent with market power. If, instead, the buyer has market power, then a specific tax welfare dominates an equal-yield ad valorem tax.

\section{References}

Delipalla, S., Keen, M., 1992. The comparison between ad valorem and specific taxation under imperfect competition. Journal of Public Economics 49, 351-367.

Suits, D.B., Musgrave, R.A., 1953. Ad valorem and unit taxes compared. Quarterly Journal of Economics 67, 598-604.

Skeath, S.E., Trandel, G.A., 1994. A Pareto comparison of ad valorem and unit taxes in noncompetitive environments. Journal of Public Economics 53, 53-71.

Wicksell, K., 1959. Taxation in the monopoly case. In: Musgrave, Shoup, (Eds.), Readings in the Economics of Taxation, Irwin, Homewood, IL, translated from 1896 original. 